\title{
The Shocking Materialities and Temporalities of Agri-capitalism
}

\begin{abstract}
Contemporary food provision is largely dominated by agricapitalism. Using the body of the chicken, the world's most pervasive source of meat protein, this paper tracks the interplay between materiality, spatiality, and temporality within agri-capitalism. It examines the myriad ways in which agri-capitalism distorts space, time, and materiality and deploys them as "fixes" to crises. It illustrates how these fixes reverberate back and forth between production and consumption to shape the spaces of alternative and mainstream food provision alike. It argues that the seemingly distinct spaces of consumption and production
\end{abstract}

LOCATED IN MATO GROSSO, THE southernmost state in Brazil's Amazon, is a "chicken meat production complex" that integrates feed milling, animal farming, and waste management. It has the capacity to kill, process, and package 500,000 chickens a day. Assuming no stoppages or delays, and $24 / 7$ production, this slaughterhouse processes roughly 1.5 million chickens per 40-day grow-out cycle, and 182.5 million chickens per 365-day year-roughly 350 chickens per minute, or nearly 6 chickens a second. The facility, however, has to be stopped for some hours each day for cleaning and regular maintenance, and there are inevitable stoppages as machinery breaks down. So, in practice, many more than 6 chickens are killed each second.

When I report these numbers to my students and in the occasional public lecture I give about "global" agriculture, the response is almost always the same: incredulity and disbelief followed by murmurs and the occasional expletive, "bloody hell." The reaction indicates that 500,000 is a lot of chickens to kill in a day, and suggests it is seen to be too many. This begs questions about what constitutes a more appropriate number of chickens to be killed-presumably somewhere between $\mathrm{o}$ and 500,000. Five hundred thousand chickens per day is at the extreme high-end of daily industrial chicken production, but perhaps not incomprehensible considering the scale and extent of agri-capitalism. Striffler (2002: 306), in an account of a similar kind of facility in North America, for instance, reports a production capacity of 200 birds a minute (just under 4 per second or 288 , ooo per day, not are in fact mutually construed and interdependent, and consequently, that shifts in consumptive practices, discourses, or temporalities and materialities cannot in themselves redress the implicit structural inequalities of agri-capitalism. This paper closes with thoughts on an insurgent food politics through which the spaces and possibilities of food can be reimagined.

Keywords: insurgent food politics, food provision, agri-capitalism, temporal fix, alternative food

accounting for stoppages), and other facilities around the world slaughter chickens in the tens and low hundreds of thousands per day - all of which feeds into 30 to 50 billion chickens killed each year for meat (see Stull and Broadway 2012).

I use these numbers intentionally to shock audiences into thinking about the spatialities and temporalities of the foods that many of us (including myself) knowingly and unknowingly consume each day, and to highlight our complicity in a system that many of us (including myself) find troubling, especially as its details are made legible. This sense of shock, however, is a slippery thing, for it remains even when contextualized and put into perspective. To illustrate this, I draw from a range of encounters during the course of my research, as well as on conversations during the didactic moments of lectures and talks. Most of the consumers I have worked with, along with students and audience members, vocalize their initial disbelief, but later tell me that when they "stop and think on it," such places as industrial-scale slaughterhouses and their material (as well as social and discursive) processes "must exist." Indeed, it takes little prompting for these same participants to connect the large quantities of relatively inexpensive foods of supermarkets with spaces and systems of production in which quantity and efficiency are so clearly prized. In these contexts, 500,000 slaughtered chickens per day (or any other "large" number) "makes sense," especially when held up next to all of those birds that are alive and waiting to be consumed around the world. But, students, audiences, and research participants (including 
myself) still report their astonishment, and remain unnerved by the implications. Contextualizing the slaughterhouse as a complex of agri-capitalism may even lead to more astonishment and become more unnerving, as if this unveiling of the commodity fetish only brings home alluded-to truths of contemporary food provision - that it inherently must rely on mass production and mass commodification and the unequal socio-ecologic relations that such things necessitate. Consumers' initial glimpses into the size and scope of agri-capitalism reveal a sense of shock that may well already exist. To paraphrase Taussig (2011), the 500,000 chickens of agri-capitalism is shocking because of its everydayness, and the everyday contexts in which such incredible circumstances are suddenly brought to light. Such revelation joins together disparate places of (food's) production with its consumption, reminding consumers and making them aware of their complicity in a system over which they have little control but is, at the same time, essential.

Agri-capitalism relies on this image of hegemony for its own reproduction. I suggest that the sense of shock ultimately stems from both the revelation of the spatialities and temporalities that reproduce agri-capitalism and the realization that these same spatialities and temporalities reproduce our bodies and our selves. It is perhaps out of this understanding that an array of food movements, including alternative food networks, healthy eating campaigns, farm to fork and other local food initiatives, and often some combination thereof have emerged to challenge agri-capitalism. Typically consumer oriented, these movements enroll a range of material as well as semiotic practices to reshape food provision, opposing and subsequently seeking to alter the normalizing spatio-temporalities that define agri-capitalism. I argue, however, that because the space-times that seemingly distinguish production from consumption are mutually construed and interdependent, consumption and shifts in consumptive practices, discourses, or indeed temporalities and materialities, cannot redress the shocking relations of production. Further, I argue that, at best, shifts in consumption offer yet more fixes to crises of capitalism by providing it with new temporalities and spatialities to colonize in its reproduction.

As I track the interplay of materiality and temporality through the body of the chicken, I reveal the myriad ways that agri-capitalism distorts space, time, and materials and deploys them as "fixes" to the crises inherent within its reproduction. Likewise, I show how these fixes reverberate through space to shape consumption-alternative, mainstream, or otherwiseand vice versa. The practices surrounding consumption, however, cannot resolve those of production because they are interrelated materially but also temporally, and are together enrolled in the hegemonic practices that in practice legitimate agri-capitalism and outlaw its threats (Gibson-Graham 2006: 55). The shocks of agri-capitalism result from paradoxes of revelation and helplessness - that its power is unquestionable and that everything we do reinforces this. Rather than end on this dire note, I offer space for optimism - that contemporary food provision can be remade through an insurgent food politics. As I detail below, such a politics operates within the normative spaces of (agri)capitalism to (re)possess, (re)take, and (re)make the geographies of food provision. I argue that such a radical politics does not seek to fix, alter, or shape agri-capitalism or indeed define itself in relation to it. Rather the power of such a politics is that it seeks to reimagine the spaces and possibilities of food altogether.

\section{Production: Damned if You Do}

The slaughter of 500,000 chickens per day is remarkable given the relatively recent widespread availability of chicken. Prior to its ubiquity, Dixon notes that chicken was a

"superior cut of meat" [and was] obtained from small specialist poultry shops in, or close to, the city markets, or from small family farms dotted around the cities. Roasting a chicken was an act of love, a symbol of a special occasion, a rare treat signalling a religious holiday. (2002: 3)

The modern broiler chicken, the one most used for commercial production, that most of us eat (regardless of where it comes from), and that haunts the Brazilian slaughterhouse and all of the others, is the product of an assembly of scientific, legal, and economic technologies (Busch 2011; Godley and Williams 2009). This assembly includes close relationships among the state, research institutions, and agri-business whose combined machinations have led to the ability to produce large numbers of chickens relatively inexpensively through agri-technologies like selective breeding and genetic manipulation for desirable traits-namely large portions of breast meat, as well as antibiotics and vitamin-enhanced feed to allow for large numbers of birds to be grown in enclosed spaces. These technologies have also culminated in a range of practices and processes colloquially known as the "Southern Model" (Boyd and Watts 1997). Through this model, all stages of bird production, from egg-hatching, final packaging, and shipping, are governed by vertically integrated agri-businesses that control the entire means of production, with the exception of husbandry. The latter is contracted to independent growers often held under stringent and binding legal agreements, including tightly worded credit obligations to buy production materials (chicks, feed, antibiotics, etc.) from the parent company to produce certain 
numbers of chickens at a certain weight for future sale at an agreed price. The effect is that profit remains centralized within the parent company and the risk of "crop failure"that is to say, there not being enough chickens, that they are diseased, underweight, or a host of other problems that may arise when mass-producing chickens-is outsourced, often to farmers who are least positioned to deal financially with such risks (Boyd and Watts 1997; Stull and Broadway 2012). This model of production has been adapted and exported around the world (Constance 2008).

Owing to the demands of such rationalized production methods as the Southern Model, a defining feature of a modern broiler chicken is the steady decrease in the time it takes from hatching to "mature" bird of sufficient slaughter weight (roughly 2 kilograms). The current industry standard is around 40 days. One animal scientist, however, tells me that the growth record is 29 days, and that the biological limit to this is probably around 20 before a "chicken is no longer viable." By contrast, a "natural" chicken can take a couple of years to reach maturity.

The implication of this comes into play when considering daily production rates of half a million. When combined with a 40-day grow-out cycle, there could be as many as 2 million birds alive and ready to cycle into the slaughterhouse. The temporal compression on the bird's life-cycle has subsequent effects on the spaces of production. The European Union $(\mathrm{EU})$, which the producer in Brazil in my example claims to follow, suggests a maximum stocking density of 18 birds per square meter. This equates to nearly 28,000 square meters per day of chickens, or 1.12 million square meters (just over 1 square kilometer) to accommodate an entire 40-day run. When it comes to feeding these animals, modern broiler chickens have feed-conversion rates (the amount of food it takes to grow to full size) of roughly 1.7 to 1 , meaning that it takes $1.7 \mathrm{~kg}$ of feed to produce $1 \mathrm{~kg}$ of live animal weight. A $2 \mathrm{~kg}$ chicken consumes nearly $3.5 \mathrm{kgs}$ of feed, which for each batch of 500,000 birds equals just over 1.5 million kgs of chicken feed. Again, multiplied by 40, this comes to 60 million kilos of chicken feed to be cycled into the system.

Thinking about these materialities as temporal cycles puts them into motion with other cycles, such as the yearly production of feed crops like soya and maize, thereby "illuminating their paths and diversions" (Appadurai 1988: 17) and exposing the political side of political economy. The slaughter-complex in Brazil is located in Mato Grosso for material reasons. Mato Grosso is associated with widespread land conversion, from primary tropical forest and "Cerrado" parklands to large-scale mechanized agriculture, with soya, a key component in chicken feed, being the state's main crop. The state's former governor, Blairo Maggi, is also owner of the Amaggi Group, a major soya producer. The slaughtercomplex is located in the state because of its agricultural capacity and proximity to soya production, as well as land and financing incentives granted by state and municipal governments. The constant repetition of eggs, chickens, feed, waste, and so forth, along with the close twinning of the political spaces of agri-capitalism, ensures the chicken's industrial reproduction. Because capitalism demands movement these materials must be cycled-kept in motion. Chicken's temporalities and materialities put agri-capitalism's other assemblies -technologies, advanced seeds, fertilizers and inputs, and technological-managerial "innovations," like contract and patent law, insurance, and finance-into motion as well, and likewise reproduces them.

Illustrating the material and spatial relationships of a temporally compressed agricultural system, these quantities, worked out using standard conversion and growth chart guides, give some idea of the size and scale of this operation and the materials required to support it. A picture of temporal compression with a "flattened," relational topology emerges from these glimpses of everyday food (Marston et al. 2005). This topology smoothens over the stickiness of place to allow the materialities and temporalities of agri-capitalism to flow freely. The fixity of place(s) encumbered with embedded social processes like tradition, or the other relationships that constituted the "good" spaces of food (Sage 2003), gives over to ever-faster production. It is little wonder that such "fast" food production (Busch 2011) goes hand in hand with the "fast" governance and "fast" policy of neoliberal capitalism (Peck and Theodore 2010). The rich and thick relations of place (Sack 1997) simply have no place within such a regime.

The intensive production of food and the rapidity of the system are fraught with contradictions. Guthman (2015), for instance, demonstrates how the (human) body absorbs agricapitalism's oversupply of maize. The body becomes a new spatial fix, in which the means of production under capitalism must colonize new territories and spaces to ensure its reproduction, to rectify this crisis (Harvey 2006). Acting as a bulking agent, this same oversupply of maize is a secondary component to chicken feed, providing material sustenance for rapid weight gain, and likewise transforming chicken, and the chicken's body, into a spatial fix. It is worth noting that in the UK, "corn fed" chickens act as a mark of distinction and command price premiums. Crises of capitalism and their spatial fixes also offer the potential for new commodities, new markets, and new avenues for consumption.

Because space and time are interrelated, spatial fixes are also temporal fixes (Jessop 2000). Keeping the system in perpetual motion, the speed of chicken production and its material 

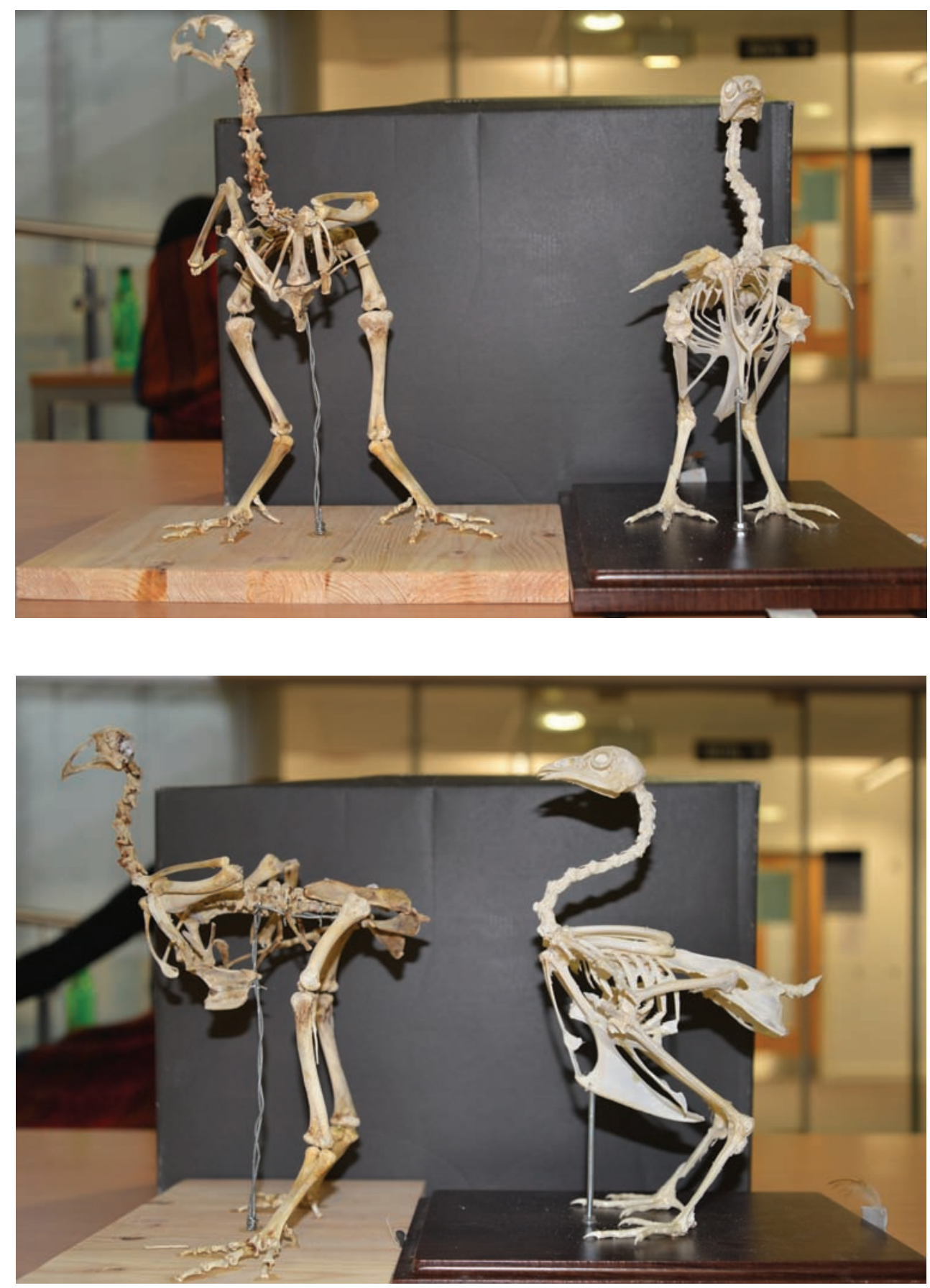

FIGURE 1A AND 1B: Contorted bones of agri-capitalism (left) versus Nature (right).

photographs by benJamin COLES (C) 2015

cycling manage crises of oversupply and overproduction. This speed, however, is imprinted on the body of the chicken. The same animal scientist who told me about the number of days it takes to grow a modern broiler has two preserved skeletons in her office. The first is a natural chicken that died after it reached maturity; it is at least two years old. Its bones are straight and strong, indicating the complete calcification of the skeletal structure, and its posture upright. This is how the skeleton of a bird whose growing cycle has not been manipulated by agriindustrial science should look. The second bird came from a supermarket. Its back is stooped from the weight of its enlarged breast; its thighbones are bowed and feet splayed to support its carriage and accommodate its unnatural weight and weight gain, and its bones are brittle. The latter suggests a lack of 
calcification, the bones of an adolescent, even though it was (beyond) full size when it was killed. Simply put, through the course of their everyday lives, modern chickens put on so much flesh, so quickly, that their skeletons do not have enough time to develop. The results are tortuous and contorted bodies whose convolutions can be followed all the way to consumption.

Up to this point I have focused on the shocking relations of chicken production within agri-capitalism, and I have illustrated why killing 500,000 chickens a day in one location could and should be shocking. Additionally by sketching out its effects in spatial, temporal, and material terms, I have hinted at what comes out of a production that has been increasingly sped up and that subsequently contorts spaces, times, and materials and iterates over a long period of timethe increasingly compressed chicken, whose totemic skeleton reminds us of this nonstop production that sustains our reproduction. In the next section, I extend my thoughts about the interplay between materiality, temporality, and spatiality and extend it to the spaces of consumption.

\section{Consumption: Damned if You Don't}

The incessant reproduction of chickens happens every day. For the consumers with whom I have spoken, ${ }^{1}$ however, although they are aware of industrial slaughterhouses and other conditions that define the modern chicken industry, its everydayness remains largely invisible, hidden behind the distanced and disconnected relations of the commodity fetish. The relations between consumers and chicken are enacted through its materiality - materializing in spaces of consumption such as supermarkets. The speed with which fast chickens are produced, along with its material and spatial cycling, exacerbates their contorted skeletal structures. But European and North American predilections for white breast meat, however influenced by the meat industry (see Haley 2001), also play an important role. The enlarged breasts that bow the femurs, splay the feet, and distend the hips and wishbone satisfy consumer demand for what is perceived to be healthier and therefore higher-value meat. They emerged through countless generations of genetic selection and manipulation in which modern broilers are bred for increased breast size. These preferences, so clearly visible in the bird's distorted bones, underscore the utility of thinking about how the materialities and temporalities of production circulate through to the spaces of food consumption. As they become a spatial (temporal) fix for agri-capitalism, chickens and chicken breasts materialize the fetishization of health and healthy eating (Guthman and DuPuis 2006). Unpacking the fetish illustrates the ways in which the foreshortened temporalities of a chicken's life are mobilized as part of the everyday materiality of food provision and healthy eating discourses.

Thinking in material terms, however, blames consumers for eating or not eating the right foods, and at the same time obscures the system at large (cf. Abbots and Coles 2013). It provides a new opportunity for agri-capitalism to create products that address concerns over its production, while at the same time ensuring its own reproduction. For instance, in recent decades, a diverse array of alternative food networks, initiatives, and movements have emerged to challenge the multiple inequities of agri-capitalism. Visible within a constellation of alternative consumption places, these alternatives position themselves as "good foods" that unmake the relations of agri-capitalism and remake them as "relations of regard" (Sage 2003). They do this materially by providing substantively different foods that fall outside agri-capitalist production regimes. For meat in general and chickens in particular, this means a resurgence of heritage breeds-those that have not been so clearly subjected to genetic selection and manipulation, as well as production methods such as using organic feed, enabling birds to roam freely in farmyards (e.g., free range), or indeed allowing birds to develop more slowly. Although costing money, the materiality of food is transformed as producers and consumers together seek new temporalities of production.

As important as these materialities and temporalities are to alternative food movements, one of their key features is the way they are highlighted as part of visual and material semiotics (Goodman 2004). Signage, imagery, and other geographical lores and knowledges (Cook and Crang 1996), such as traceability, become key features of alternative foods, generating a shared system of meanings that positions the foodstuffs and their (imagined) geographies in an oppositional relation, that is to say as an alternative, to agri-capitalism (Coles and Crang 2011). For instance, the promotional literature for chickens on sale in a famous London market, popular with those who seek distinctive foods with geographical pedigree and who subscribe to an ethos of alternative foods more generally, reads:

[a] combination of the best of the old with the best of the new. The breed is developed [to carry] more breast meat and is of a paler colour . . . Raised in a high welfare environment, they are fully free-range, fed a natural diet and grown slowly to full maturity, up to 75 days. The meat has a delicate texture and excellent flavour.

Surrounding photographs as well as signage, narratives about places of production, and other elements of visual material culture combine in the market to produce a distinctive material-semiotic that among other things seeks to 
defetishize foodstuffs by placing them first within an alternative consumption space, and then an alternative geography (Coles 2014).

These geographies mobilize multiple temporalities to combine history and nostalgia with these materialities to fashion an imagined food landscape. Within this landscape, farms and farmers have names and faces (as sometimes do the animals), and other apparent social relations, to constitute places "thick" with embedded meanings about production (Sack 1992, 1997). Critically, within this landscape, the rapid cycling of materials, the compressed and elongated spaces of production, and the twisted and contorted bodies of chickens, all of which are the product of an agri-capitalist temporality, are slowed down. An alternate time-space that draws from natural processes and cycles of food emerges to reorder agri-capitalism. The result is an alternate geography that rematerializes food in general and chickens more specifically, and is juxtaposed with the flat ontologies of agri-capitalism and its placeless foodscape (Holloway and Kneafesy 2000).

As the images of such foods, along with the foods themselves, have begun to appear in supermarket aisles, recent evidence suggests that the material semiotics of alternative food, along with some of the materialities they support, have been appropriated by mainstream food provision (Goodman et al. 2012). This calls into question the extent to which food can be rematerialized by altering its temporalities. For instance, Gunderson (2014: 116) argues that "de-fetishization" "constitutes a 'third" layer of commodity fetishism - a distortion of reality - which reifies and reproduces the fundamental processes of capitalism by making the commodity form the solution to its own mystifications." Moreover, focusing on the interplay between materiality and temporality raises a fundamental paradox of food-that inequities of its production can be undone by shifting the relations of its consumption, however "nicer" that consumption may be seen to be (West and Domingos 2012).

The reason for these paradoxes, I suggest, is that temporalities are mobile along with materiality-meaning that the temporal relations that define agri-capitalism, however compressed or elongated, circulate with its materialities, making them the same as those that alternative foods seek to redefine. The materiality of chicken reveals this. Unlike "red" meat, such as beef or game, which benefit from an aging process, once killed, poultry has a short shelf life. This "life" can only be extended as it is chilled to near freezing or freezing temperatures. One reason why it took so long, relatively speaking, for chickens to develop into a popular food staple is that the infrastructure required to manage its materiality, from slaughter to kitchen - to keep it cold and therefore fresh-was difficult, expensive to establish, and only came about with the development of the "cold chain" - a constellation of actors and (other) materials that keep chicken cold from the slaughterhouse, to the distribution center, to the supermarket, or indeed market stall, all the way to the kitchens of consumers. And all chickens, regardless of pedigree, require this chain.

So while the Brazilian slaughterhouse is necessarily located within the agri-capitalist political economy of Mato Grosso, and the chickens of alternative markets embedded in the relations of regard within alternative food movements, chickens generally speaking are embedded within an array of coordinating production technologies (Shove et al. 2012) that define and are defined by agri-capitalism itself. In other words the timespaces of chickens are the same. They are manipulated, controlled, and performed to suit the spaces of consumption while maintaining the spaces of reproduction. And, so long as alternative and conventional foods are held in relation, agri-capitalism's hegemony is bound to continue. Thus the enduring shock stems from the realization that within capitalism, and the divisions of labor that distinguish consumers from producers and vice versa, the alternative cannot exist.

\section{Conclusion: Just Don’t}

Thus far I have constructed a bleak scenario for food-a paradox whose resolution is not readily apparent. However, to think about possibilities I reach back to my lectures with students, and my intention to shock (again), by paraphrasing anthropologist David Graeber. Commenting on the power of social construction, and stating that capitalism is "merely" a social construction, he notes that if we wanted to stop doing capitalism tomorrow, then tomorrow, we could wake up and stop doing capitalism (Graeber 2015). This is, of course, a provocative statement, and my students rightly point out the many possible practical issues that inhibit the simple stopping of the dominant political economic structure that defines most of our contemporary existence.

Framing one version of alternative and diverse economies, Gibson-Graham comments:

representations of capitalism are a potent constituent of the anticapitalist [alternative food in this context] imagination, providing images of what is to be resisted and changed as well as intimations of the strategies, techniques, and possibilities of changing it . . . in this sense "capitalist" hegemony operates not only as a constituent of, but also a brake upon, the anticapitalist imagination. (1996: 3 )

I imply in the previous section that by refashioning the temporalities of consumption to rematerialize food production, 
many alternative food networks, initiatives, and movements rely on the relations of agri-capitalism to define the terms of their resistance. And because agri-capitalism is adept at using its own challenges and contradictions to seek out new markets and opportunities, such alternative projects are bound to fail.

A recent field encounter in inner-city Britain, however, sheds light on the creativity of Gibson-Graham's project. The study site is a community garden located in an interstitial "dead-zone" (Doron 2008), a (formerly) vacant field ostensibly owned by the adjacent primary school that prior to its reclamation as a garden was blighted by dog walking and fly tipping (illegal dumping), among other forms of antisocial behavior. The surrounding community is composed mostly of social housing residents, whose own social reproduction is increasingly precarious as new forms of urban austerity take hold. It has high rates of food insecurity and associated poor health indicators. Indeed, surrounding parts of the neighborhood are slated for "redevelopment," a move that opens the door for privatization, gentrification, and subsequent displacement. Unlike the weak spaces where alternative economies challenge capitalism's hegemony (Lee et al 2003), this site represents the vanguard of retrenched and aggressive neoliberalism-capitalism at its perhaps most powerful. The garden grows an array of fruits, vegetables, and herbs and hosts a wood-fired oven for bread baking, and has become a focal point for community gatherings. Crucially, for this article, the garden also has chickens. Although available to any passerby and volunteers, all of the produce produced collectively in the garden, including the chickens, is consumed by the community. And community members indicate that the garden, its foods, and its presence have got them thinking about food, and food issues more generally - such as where it comes from, its effects on their bodies, and health and nutrition.

I suggest that this garden is a radically emergent space. It falls outside agri-capitalism not by re-temporalizing its relations, but, by default, by community members claiming the space to manage their own reproduction. The spatial and temporal relations of the garden, and its community members, do not seek to challenge agri-capitalism, nor do they define themselves by relating to agri-capitalism. Rather the community is motivated by far simpler objectives, albeit ones that hide complexity: to grow enough food to help sustain itself. In doing so, the garden does manage to remake relationships with food, to use space and time to rematerialize what community members eat and, by extension, their bodies and that of the community at large. This project is not scalable in the sense that it can be expanded. The land on which the garden sits is limited, and only recently and precariously secured from the forces of redevelopment. But in this lies its insurgent power-to be fluid, mobile, and adaptive. This makes it a space of hope and potential. Here, food and the body are neither frontiers of agri-capitalist development nor repositories for its overproduction. The shocks of 500,000 chickens per day and the agri-capitalism they represent require too much space and time. The connections between production and consumption-the interplay between materiality, temporality, and spatiality that reproduces the bodies of individuals and that of the community-are too visible. Simply put, there is no room for them. This insurgent space, however, is also shocking. But for different reasons: It manages to flourish in its margins not despite a political economy stacked against it, but because of it. The production and consumption of food needs more spaces like this, whose affront to the very system it seeks to erase is a shock in itself. @

NOTE

1. Ranging from high to low investors into the array of networks, initiatives, and movements that have come to be known as "alternative" foods, these consumers are broadly speaking middleclass British, from urban and rural locations around the UK.

\section{REFERENCES}

Abbots, Emma-Jayne, and Benjamin Coles. 2013. "Horsemeat-gate: The Discursive Production of a Neoliberal Food Scandal." Food, Culture and Society 16(4): 535-50.

Appadurai, Arjun. 1988. The Social Life of Things: Commodities in Cultural Perspective. Cambridge: Cambridge University Press.

Boyd, William, and Michael Watts. 1997. "Agro-Industrial Justin-Time: The Chicken Industry and Postwar American Capitalism." In Globalising Food: Agrarian Questions and Global Restructuring, ed. David Goodman and Michael Watts. New York: Routledge.

Busch, Lawrence. 2011. Standards: Recipes for Reality. Cambridge, MA: MIT Press.

Coles, Benjamin F. 2014. "Making the Market Place: A Topography of Borough Market, London." Cultural Geographies 21(3): 515-23. - and Philip Crang. 2011. "Placing Alternative Consumption: Commodity Fetishism in Borough Fine Foods Market, London." In Ethical Consumption: A Critical Introduction, ed. Tanya Lewis and Emily Potter. London: Routledge.

Constance, Douglas H. 2008. "The Southern Model of Broiler Production and Its Global Implications." Culture and Agriculture 3०(1-2): 17-31.

Cook, Ian, and Philip Crang. 1996. “The World on a Plate: Culinary Culture, Displacement and Geographical Knowledges.” Journal of Material Culture 1(2): 131-53.

Dixon, Jane. 2002. The Changing Chicken: Chooks, Cooks and Culinary Culture. Sydney: UNSW Press.

Doron, Gil. 2008. ““. . . those marvellous empty zones on the edge of cities': Heterotopia and the 'Dead Zone." In Heterotopia and the City: Public Space in a Postcivil Society, ed. Michiel Dehaene and Lieven De Cauter, 203. New York: Routledge.

Gibson-Graham, Julie-Katherine. 1996. The End of Capitalism (as We Knew It): A Feminist Critique of Political Economy; with a New Introduction. Minneapolis: University of Minnesota Press. . 2006. A Postcapitalist Politics. Minneapolis: University of Minnesota Press.

Godley, Andrew, and Bridget Williams. 2009. "Democratizing Luxury and the Contentious 'Invention of the Technological Chicken’ in Britain.” Business History Review 83(2): 267-90. 
Goodman, David, E. Melanie DuPuis, and Michael K. Goodman. 2012. Alternative Food Networks: Knowledge, Practice, and Politics. London: Routledge.

Goodman, Michael K. 2004. "Reading Fair Trade: Political Ecological Imaginary and the Moral Economy of Fair Trade Foods." Political Geography 23(7): 891-915.

Graeber, David. 2015. The Utopia of Rules: On Technology, Stupidity, and the Secret Joys of Bureaucracy. London: Melville House.

Gunderson, Ryan. 2014. "Problems with the Defetishization Thesis: Ethical Consumerism, Alternative Food Systems, and Commodity Fetishism." Agriculture and Human Values 31(1): 109-17.

Guthman, Julie. 2015. "Binging and Purging: Agrofood Capitalism and the Body as Socioecological Fix." Environment and Planning A 47(12): 2522-2536.

_ and Melanie DuPuis. 2006. "Embodying Neoliberalism: Economy, Culture, and the Politics of Fat." Environment and Planning D: Society and Space 24(3): 427-48.

Haley, Mildred M. 2001. "Changing Consumer Demand for Meat: The US Example, 1970-2000.” In Changing Structure of Global Food Consumption and Trade, by Anita Regmi, 41-48. Economic Research Service and US Department of Agriculture.

Harvey, David. 2006. The Limits to Capital (new and fully updated edition). London and New York: Verso.

Holloway, Lewis, and Moya Kneafsey. 2000. "Reading the space of the farmers' market: a preliminary investigation from the UK." Sociologia Ruralis 40(3): 285-299.

Jessop, Bob. 2000. "The Crisis of the National Spatio-Temporal Fix and the Tendential Ecological Dominance of Globalizing Capitalism." International Journal of Urban and Regional Research 24(2): 323-60.
Leyshon, A., Lee, R. and Williams, C.C. eds., 2003. Alternative Economic Spaces. London: Sage.

Marston, Sallie A., John Paul Jones, and Keith Woodward. 2005. "Human Geography without Scale." Transactions of the Institute of British Geographers 30(4): 416-32.

Peck, Jamie, and Nik Theodore. 2010. "Mobilizing Policy: Models, Methods, and Mutations." Geoforum 41(2): 169-74.

Sack, Robert David. 1992. Place, Modernity, and the Consumer's World: A Relational Framework for Geographical Analysis. Baltimore: Johns Hopkins University Press. - 1997. Homo Geographicus: A Framework for Action, Awareness, and Moral Concern. Baltimore: Johns Hopkins University Press.

Sage, Colin. 2003. "Social Embeddedness and Relations of Regard: Alternative 'Good Food' Networks in South-west Ireland." Journal of Rural Studies 19(1): 47-6o.

Shove, Elizabeth, Mika Pantzar, and Matt Watson. 2012. The Dynamics of Social Practice: Everyday Life and How It Changes. Woodland Oaks, CA: Sage.

Striffler, Steve. 2002. "Inside a Poultry Processing Plant: An Ethnographic Portrait." Labor History 43(3): 305-13.

Stull, Donald, and Michael Broadway. 2012. Slaughterhouse Blues: The Meat and Poultry Industry in North America. Scarborough, ON: Nelson Education.

Taussig, Michael. 2011. I Swear I Saw This: Drawings in Fieldwork Notebooks, Namely My Own. Chicago: University of Chicago Press.

West, Harry G., and Nuno Domingos. 2012. "Gourmandizing Poverty Food: The Serpa Cheese Slow Food Presidium.” Journal of Agrarian Change 12(1): 120-43. 